\title{
Influência da cobertura morta sôbre a umi- dade de um solo cultivado com Cafeeiro (*)
}

\author{
Moacyr de O. C. do Brasil Sobrinho \\ Francisco de $A$. F. de Mello
}

Escola Superior de Agricultura «Luiz de Queiroz»

(*) Recebido para publicação em 29/10/1960.

Este trabalho foi apresentado na Seç̧ão de Ciências Agronômicas na XIl Reunião Anual da Sociedade Brasilcira para o Progrcsso da Ciência, realizado em Piracicaba, de 3 a 7/7/60. 


\section{INTRODUÇÃO}

$O$ presente trabalho faz parte de um estudo da influência da cobertura morta sôbre algumas propriedades físicas e quimicas de um latosolo vermelho amarelo plantado com café.

O papel da cobertura morta sôbre a umidade do solo tem preocupado diversos autores. Uma bôa revisão dos trabalhos publicados nesse sentido foi feita por JACKS et al. (1955). No Brasil, MEDCALF (1956) empregou como cobertura morta em café, composto de curral e os capins colonião e gordura encontrando resultados favoráveis sôbre a conservação da umidade de um solo arenito Baurú.

\section{MATERIAL E MÉTODOS}

$O$ ensaio foi realizado em una área contendo 100 cafeeiros sendo a metade deles com cobertura morta e a outra metade sem cobertura morta. O solo do experimento era um latosolo vermelho amarelo situado em terras da Escola Superior de Agricultura "Luiz de Queiroz" e cujas caracteristicas quimicas e físicas são citadas por RANZANI et al. (1959). O café era da variedade Bourbon amarelo (Coffea arabica L., var. Bourbon, forma amarela) e tinha dois anos de idade quando foram iniciados os tratamentos com grama Batatais (Paspalum notatum) procedente do parque daquele estabelecimento. Manteve-se durante todo o tempo uma camada de 10 a $15 \mathrm{~cm}$ de espessura dêsse material cobrindo toda a superfície do terreno na parte com cobertura morta.

Na parte exposta ao sol o café foi conservado no limpo através das capinas necessárias, em número de 4 ou 5 por ano.

Amostras de solo de 3 diferentes profundidades foram tomadas ao redor de 15 em 15 dias dos talhões "com cobertura morta" e "sem cobertura morta" durante o periodo de 1/3/1957 a 15/8/1958, com falta de algumas épocas devido à ocorrência de períodos chuvosos. As datas de coleta foram sempre que possível nos dias 1 e 15 de cada mês. Quando chovia na ocasião das amostragens as coletas eram feitas 3 dias após o cessamento das chuvas. Devido a tal motivo, em diversas épocas as amostragens foram feitas fora das datas especificadas, ou mesmo, deixaram de ser executadas, quando as chuvas cessavam muito além dos dias determinados.

As amostras eram colhidas com trado, em duplicata, ao acaso, nos talhões com e sen cobertura morta. Ó inicio das amostragens se deu a partir da dátá da primeira adição do referido material. 
As profundidades eram 3, a saber: superfície $(0-2 \mathrm{~cm}), 2-15 \mathrm{~cm}$ e $15-30 \mathrm{~cm}$.

As determinações de umidade foram feitas segundo CATANI et al. (1955).

\section{RESULTADOS E DISCUSSÃO}

As percentagens de umidade do solo dos dois tratamentos referentes às profundidades, médias de 2 repetições, se acham no Quadro I. $\mathrm{Na}$ análise estatística foram usados êsses mesmos dados médios sendo que as suas análises de variância se acham nos Quadros II e III.

A análise dos dados mostrou uma diferença altamente significativa para tratamentos ( $5 \mathrm{G}$. L.), pelo teste $v$ de BRIEGER (BRIEGER, 1946). As análises de variância dos contrastes grupo $\mathrm{A} \times$ grupo $\mathrm{B}$, dentro do grupo $\mathrm{A}$ e dentro do grupo $\mathrm{B}$ revelaram diferenças altamente significativas (à ordem de $0,1 \%$ pelo teste v) entre os dois grupos A e B e dentro do grupo B. Dentro do grupo A houve significância à ordem de $1 \%$ pelo mesmo teste.

A diferença mínima significativa pelo teste de Tukey (PIMENTEL GOMES, 1960) a $5 \%$ entre as médias correspondentes aos seis tratamentos foi igual a $2,12 \%$ :

$$
\Delta=\frac{\mathrm{s}}{\sqrt{\mathrm{r}}}
$$

$$
\mathrm{q}=4,03
$$

\section{Tratamento}

$\begin{array}{rllr}\text { Grupo A 1) } & \text { Superfície } & 23,21 \\ \text { com cobertura } & \text { 3) } & 15 \text { a } 15 \mathrm{~cm} & 21,51 \\ & \text { 4) } & 150,53 \\ \text { Grupo B } & \text { 5) } & \text { Superfície } & 20 \\ \text { sem cobertura } 15 \mathrm{~cm} & 9,31 \\ & \text { 6) } 15 \text { a } 30 \mathrm{~cm} & 16,26 \\ & \text { d.m.s. }=2,12 \% & 18,40\end{array}$

Dentro do grupo A o tratamento $n .^{\circ} 1$ não se mostrou superior ao tratamento n. ${ }^{\circ} 2$, mas foi superior ao de n. ${ }^{\circ} 3$. Os tratamentos ns. 2 e 3 não diferiram entre si.

Dentro do grupo B o tratamento n. 4 foi menor do que os outros dois. 10 n. 5 , menor que o $n .^{\circ} 6$. 
Num confronto geral pode-se observar que isoladamente qualquer tratamento do grupo A (com cobertura morta) mostrou-se superior a qualquer dos 3 tratamentos do grupo B (sem cobertura morta).

Pela interpretação estatística pode-se notar que a cobertura morta foi eficiente para a conservação da umidade do solo, sendo o seu efeito mais pronunciado nos períodos mais sêcos e principalmente nas camadas da superfície. Para melhor elucidação do seu comportamento, no Quadro IV foram colocados os dados de queda de chuva durante os meses em que decorreu o experimento.

Examinando os dados do Quadro I observa-se que os teores de umidade dos tratamentos com cobertura não variam muito com as diversas profundidades ou, quando mostram variação, os valores maiores se encontram na camada superficial. O contrário sucede com os dados dos tratamentos sem cobertura morta, cuja variação é maior e na quase totalidade dos casos o teor de umidade aumenta com a profundidade.

MEDCALF (1956) encontrou resultados semelhantes quando empregou cobertura morta en solo arenito de Bauru.

\section{CONCLUSOES}

O trabalho permite concluir que a cobertura morta mostrou-se eficiente na conservação da umidade do solo estudado que era um latosolo vermelho amarelo. O seu efeito foi mais pronunciado nos periodos mais sêcos e principalmente na camada superficial.

\section{RESUMO}

O presente trabalho é parte de um estudo da influência da cobertura morta sôbre algumas propriedades físicas e químicas de um latosolo vermelho amarelo plantado com café. Nele os autores relatam apenas os resultados obtidos sôbre a conservação da umidade do solo, concluindo que a cobertura morta mostrou-se eficiente nesse particular. O seu efeito foi mais pronunciado nos periodos mais sêcos e principalmente na camada superficial.

\section{SUMMARY}

The present paper is part of a study about the influence of mulching on some chemical and physical properties on a soil 
"latosolo vermelho amarelo" of a coffee plantation. The authors reported only the results obtained on soil moisture conservation and concluded that the mulching had a better effect. The results were more effective on dry weather and mainly on soil upper layer about 0 to $2 \mathrm{~cm}$.

\section{LITERATURA CITADA}

BRIEGER, F. G. - 1946 - Limites unilaterais e bilaterais na análise estatística, Bragantia, 1946, vol. 6, n.o 10. Inst. Agron. de Campinas, Secretaria da Agric. do E. S. Paulo.

CATANI, R. A., J. ROMANO GALLO e H. GARGANTINI - 1955 Amostragem de solo, métodos de análise, interpretação e indicações gerais para fins de fertilidade. Boletim n.o 69 - Inst. Agronômico de Campinas - Secr. da Agric. do E. S. Paulo.

JACKS, G. V., W. D. BRIND and ROBER SMITH - 1955 - Mulching - Technical Comp. n.o 49 of the Comm. Bur. of Soil Sci. Comm. Agr. Bur. Farnham Royal, Bucks, England.

MEDCALF, J. C. - 1956 - Estudos preliminares sôbre aplicação de cobertura morta em cafeeiros novos do Brasil. Boletim n.o $12-$ IBEC Res. Inst., New York.

PIMENTEL GOMES, F. - 1960 - Curso de Estatística Experimental - E. S. A. «Luiz de Queiroz», U. S. P., Piracicaba, E. S. Paulo. 
$$
\text { . }
$$ 
QLADRO I

DATAS DAS AMOSTRAGENS NOS ANOS DE 1957 - 1958 E DADOS MÉDIOS DE UMIDADE

\begin{tabular}{|c|c|c|c|c|c|c|c|c|c|c|c|c|c|c|c|c|c|c|c|c|c|c|c|c|c|}
\hline Com Cobertura morta & $1 / 3 / 57$ & $15 / 3 / 57$ & $1 / 4 / 57$ & $15 / 4 / 57$ & $15 / 5 / 57$ & $1 / 6 / 57$ & $15 / 6 / 57$ & $1 / 7 / 57$ & $15 / 7 / 57$ & $1 / 8 / 57$ & $15 / 8 / 57$ & $1 / 9 / 57$ & $15 / 9 / 57$ & $1 / 10 / 57$ & $\mid 15 / 10 / 57$ & $1 / 11 / 57$ & $15 / 3 / 58$ & $15 / 4 / 58$ & $1 / 5 / 58$ & $15 / 5 / 58$ & $1 / 6 / 5^{8}$ & $1 / 7 / 58$ & $15 / 7 / 58$ & $1 / 8 / 58$ & $15 / 8 / 58$ \\
\hline $1-$ Superfície & 16,1 & 18,7 & 20,6 & 21,7 & 20,0 & 18,9 & 20,3 & 22,6 & 20,9 & 22,4 & 22,7 & 21,8 & 23,0 & 24,1 & 20,4 & 24,7 & 26,1 & 27,3 & 26,5 & 29,3 & 28,5 & 25,6 & 24,8 & 23,7 & 29,0 \\
\hline $2-15 \mathrm{~cm}(A)$ & 21,0 & 14,6 & 21,3 & 21,4 & 20,5 & 19,1 & 19,6 & 19,0 & 19,6 & 21,6 & 21,5 & 22,2 & 21,2 & 21,7 & 20,7 & 22,3 & 21,9 & 23,0 & 22,5 & 22,3 & 23,0 & 20,7 & 22,5 & 22,3 & 22,8 \\
\hline $3-30 \mathrm{~cm}$ & 19,6 & 19,8 & 21,6 & 20,8 & 20,1 & 18,6 & 19,5 & 19,5 & 19,3 & 19,5 & 20,0 & 21,6 & 21,4 & 19,6 & 20,5 & 20,2 & 21,7 & 28,2 & 21,1 & 22,5 & 22,1 & 19,6 & 22,3 & 20,9 & 18,4 \\
\hline
\end{tabular}

Sem Cobertura morta

\begin{tabular}{|c|c|c|c|c|c|c|c|c|c|c|c|c|c|c|c|c|c|c|c|c|c|c|c|c|c|}
\hline $4-$ Superfície & 16,2 & 5,2 & 21,6 & 15,7 & 5,2 & 5,2 & 4,6 & 3,9 & 4,5 & 8,4 & 7,2 & 6,7 & 11,4 & 4,1 & 3,2 & 18,9 & 3,2 & 18,3 & 8,7 & 9,0 & 16.1 & 4,1 & 12,1 & 12,1 & 4,8 \\
\hline $5-15 \mathrm{~cm}(\mathrm{~B})$ & 18,1 & 15,2 & 21,0 & 28,2 & 13,4 & 10,1 & 12,0 & 11,9 & 13,9 & 16,0 & 15,9 & 15,4 & 17,4 & 18,5 & 14,3 & 17,9 & 15,0 & 18,3 & 15,0 & 17,4 & 17,2 & 16,8 & 16,4 & 16,9 & 14,8 \\
\hline $6-30 \mathrm{~cm}$ & 22,6 & 19,6 & 21,3 & 20,2 & 19,1 & 16,8 & 17,8 & 20,3 & 17,9 & 19,0 & 17,8 & 17,8 & 18,0 & 20,0 & 17,8 & 20,1 & 16,4 & 19,4 & 17,4 & 16,3 & 18,5 & 16,2 & 16,9 & 18,3 & 14,9 \\
\hline
\end{tabular}


QUADRO II

ANÁLISE DA VARIÂNCIA

\begin{tabular}{l|r|r|r|r|r|r}
\hline $\begin{array}{c}\text { Causa dla } \\
\text { variação }\end{array}$ & G.L. & S.Q. & Q.M. & Erro & $v$ & Signif. \\
\hline Blocos & 27 & 595,2 & 22,17 & - & - & \\
Tratamentos & 5 & $3.422,0$ & 684,40 & 26,16 & 9.3 & $* * *$ \\
Resíduo & 135 & $1.052,1$ & 7,793 & 2,79 & - & \\
\hline TOTAIS & 167 & $5.068,4$ & - & - & - & - \\
\hline
\end{tabular}

Q(TAl)RO III

ANÁliSE DA VARIÂNCIA

(decomposição dos tratamentos)

\begin{tabular}{l|r|r|r|r|r|r}
\hline \multicolumn{1}{c|}{$\begin{array}{c}\text { Causa da } \\
\text { variação }\end{array}$} & i.L.. & S.Q. & P.M. & Erro & $v$ & Signif. \\
\hline Girupo A x Grupo B & 1 & $2.047,2$ & $2.047,2$ & 45,24 & 16,2 & $* * *$ \\
Dentro do Grupo A & 2 & 110,6 & 55,3 & 7,44 & 2,7 & $* *$ \\
Dentro do Girupo B & 2 & $1.264,1$ & 632,0 & 25,14 & 9,0 & $* * *$ \\
Resicluo & 135 & $1.052,1$ & 7,793 & 2,79 & - & - \\
\hline
\end{tabular}




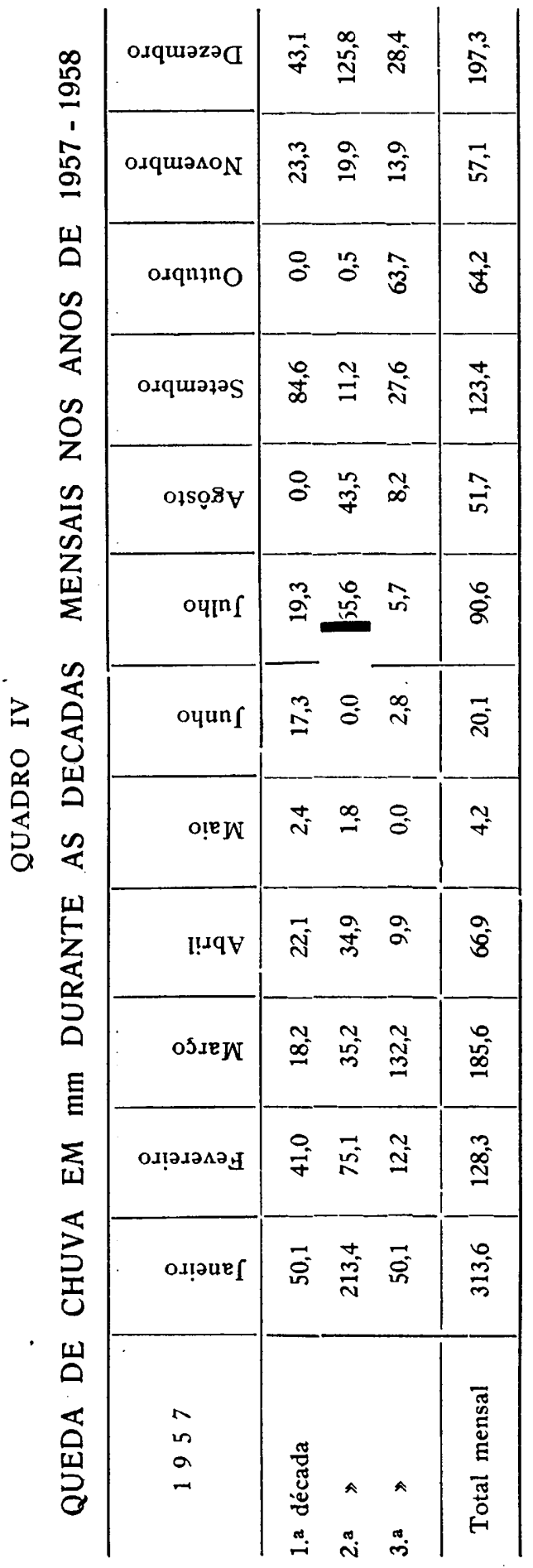

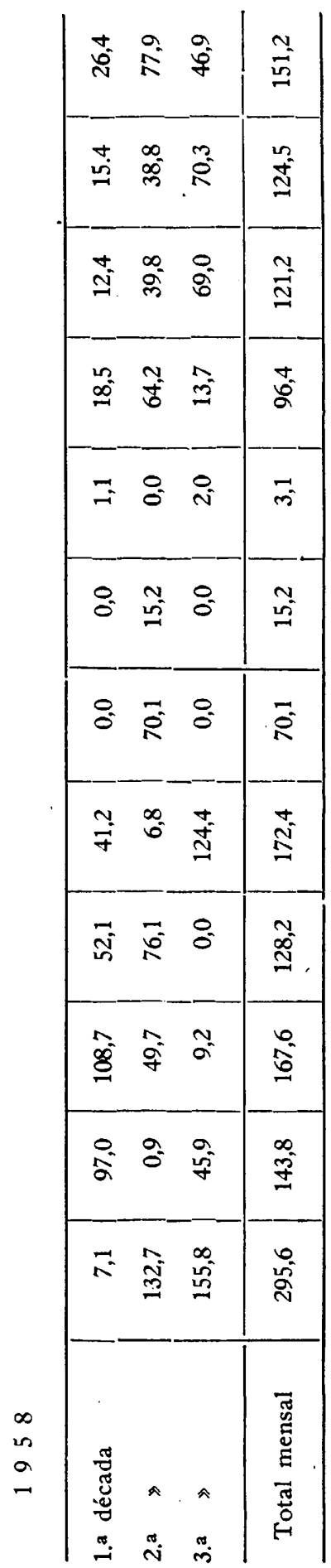

